\title{
Women and Chronic Obstructive Pulmonary Disease
}

\author{
Christine Jenkins, MD, FRACP
}

Concord Hospital Sydney, The George Institute for Global Health Sydney, Faculty of Medicine, UNSW, University of Sydney, Sydney, Australia

\section{ABSTRACT}

Around the world, chronic obstructive pulmonary disease (COPD) is affecting women more than ever before. Increased smoking rates amongst women in the last 60 years, and the continued domestic and occupational exposure of women in low-income countries to biomass fuels and smoke have greatly increased the incidence of COPD in women. COPD presents differently in men and women, and women experience a higher symptom burden, rate of exacerbations and greater risk hospitalization. Additionally, women appear to be more vulnerable to the effects of smoking and develop airways disease at lower doses than men. Despite this, women are often under-represented in clinical trials, very few analyses address sex-specific differences in response to treatment, and management is rarely tailored to the specific needs of women with COPD. This article discusses the evidence and some of the potential approaches to address the burden of COPD in women. (BRN Rev. 2018;4:4-15)

Corresponding author: Christine Jenkins, christine.jenkins@sydney.edu.au

Key words: COPD. Sex. Burden of disease. COPD symptoms. 


\section{WOMEN AND COPD}

Chronic obstructive pulmonary disease (COPD) is now the third most frequent cause of death in the world, behind ischaemic heart disease and stroke. It will be a major ongoing public health problem for several decades to come due to its increasing international prevalence, ageing populations, continued tobacco smoking and indoor, outdoor and occupational pollution exposure ${ }^{1}$. It is becoming clear that COPD affects men and women differently, develops in response to different exposures and doses, and presents clinically in a different way. In the age of precision medicine, it is important to understand these differences in order to address them proactively, and to appreciate that more effective, targeted approaches to prevention and management of COPD in men and women will reduce its burden and impact on health, productivity and mortality.

\section{EPIDEMIOLOGY OF COPD IN WOMEN}

\section{Prevalence of COPD in women}

The prevalence of COPD in women is lower than in men in most of the studies, but higher than would be expected from tobacco smoke exposure alone. In the international Burden of Obstructive Lung Disease (BOLD) study ${ }^{8}$, using a standardized protocol across 12 sites, the overall prevalence of Global Initiative for Chronic Obstructive Lung Disease (GOLD) stage II or higher COPD was 10.1\% (standard error [SE] 4.8) overall, $11.8 \%$ (7.9) for men, and 8.5\% (5.8) for women. The prevalence increased with age, being $7.5 \%$ (95\% confidence interval [CI] 5.7 to 9.4) among people aged $\geq 40$ years and $29.2 \%$ (18.1 to 40.2) among people aged $\geq 75$. In relation to tobacco smoke exposure, site-specific packyear odds ratios (ORs) varied significantly in women but not in men, suggesting there were several contributors to the risk of COPD in women, apart from tobacco exposure.

COPD prevalence has risen more rapidly in women than men in many high-income countries over the last two decades ${ }^{1-6}$. This reflects increased longevity, improved survival from cardiovascular disease and the change in tobacco smoking uptake that began in the second half of the 20th century, which gradually saw the number of women smoking increase to match male smoking rates, and in some countries, overtake them, even though smoking prevalence overall has fallen 7 . In low- and middle-income countries the prevalence of smoking amongst women is still relatively low compared to males, but women experience many other sources of smoke exposure, greatly increasing their risk of developing COPD.

\section{Mortality in women}

Age-adjusted all-cause mortality rates are higher in men than women and this applies also to COPD, even after controlling for COPD severity. In a United Kingdom (UK) study ${ }^{8}$, while COPD prevalence was climbing in women and had plateaued in men, all-cause mortality in people with COPD was higher in men (106.8 versus 82.2 per 1000 person-years) than in women, with a consistently increased relative risk in men of 1.3 even after controlling for the severity of COPD. Significantly increased mortality rates were also observed in adults aged less than 65 years. However, women suffer more morbidity from COPD than men, as will be described below. 


\section{Causes of COPD in women: exposure dose and effects differ to men}

Women appear to be more susceptible to the effects of cigarette smoke than men, for a given number smoked/day, and total intake ${ }^{9-13}$ (Fig. 1). There are many possible mechanisms for this, including different molecular and metabolic responses to cigarette and biomass smoke, different airway geometry, patterns of inhalation, intensity and diversity of exposure, and cellular vulnerability ${ }^{14-18}$. In a study from Nanjing China exploring the relationship between cigarette smoking and COPD among urban and rural adults $>35$ years old, the overall prevalence of diagnosed COPD was significantly higher among men than in women (7.2\% versus $4.7 \%$, p < 0.000); however, the relationship between prevalence of COPD and total cigarette smoking was dose-dependent by gradient in women, while only men with the highest cigarette smoking rates were more likely to have COPD ${ }^{19}$. Similarly, in an analysis ${ }^{20}$ of the medical records of 844 COPD patients in Finland, women reported significantly fewer packyears than men. Compared to the men, the women had less advanced airway obstruction, but more severe gas transfer impairment. Parenchymal damage measured by diffusion capacity correlated more strongly with forced expiratory volume in one second $\left(\mathrm{FEV}_{1}\right) \%$ predicted in women than men. This cohort showed several significant gender-dependent differences in their clinical presentation including having a lower body mass index (BMI), and more psychiatric conditions, especially depression, but men being more likely to have cardiovascular diseases, diabetes and alcoholism.

Multiple studies from different regions of the world have suggested both increased risk and greater impact of COPD in women who smoke. Two longitudinal Danish studies ${ }^{6}$, the Copenhagen City Heart Study and the Glostrup Population Study combined, found that after adjusting for smoking, women had a 1.5 times greater probability of COPD-related hospitalizations than men, which could not be accounted for by higher rates of hospitalization in women in general. For each pack-year of smoking, women had greater excess loss of $\mathrm{FEV}_{1}$ in mls per year. In another study, women were disproportionately represented in the subset of patients with COPD with severe disease despite minimal tobacco smoke exposure (defined as $<20$ pack-years) ${ }^{7}$. Women were also more likely to present with COPD before the age of 60 years.

\section{Increased susceptibility of women to tobacco and biomass smoke inhalation}

In the BOLD study, sex-related differences in smoking patterns (especially in the ever-smoked group) were recorded for almost all sites, and mean pack-years were consistently higher for men than for women. The prevalence of stage II or higher COPD was $10.1 \%$ (SE 4.8) overall, $11.8 \%$ (7.9) for men, and 8.5\% (5.8) for women, but this difference hides the lower exposure to and smoking rates of women, and suggests that factors other than cigarette smoking contribute to COPD prevalence in women.

The recently published study from the UK Biobank ${ }^{10}$ confirms these findings of increased susceptibility of women to cigarette smoke. In a very large database of approximately 500,000 subjects aged 40 to 69 years, the association of airflow obstruction and smoking was stronger in women than in men. There was a 


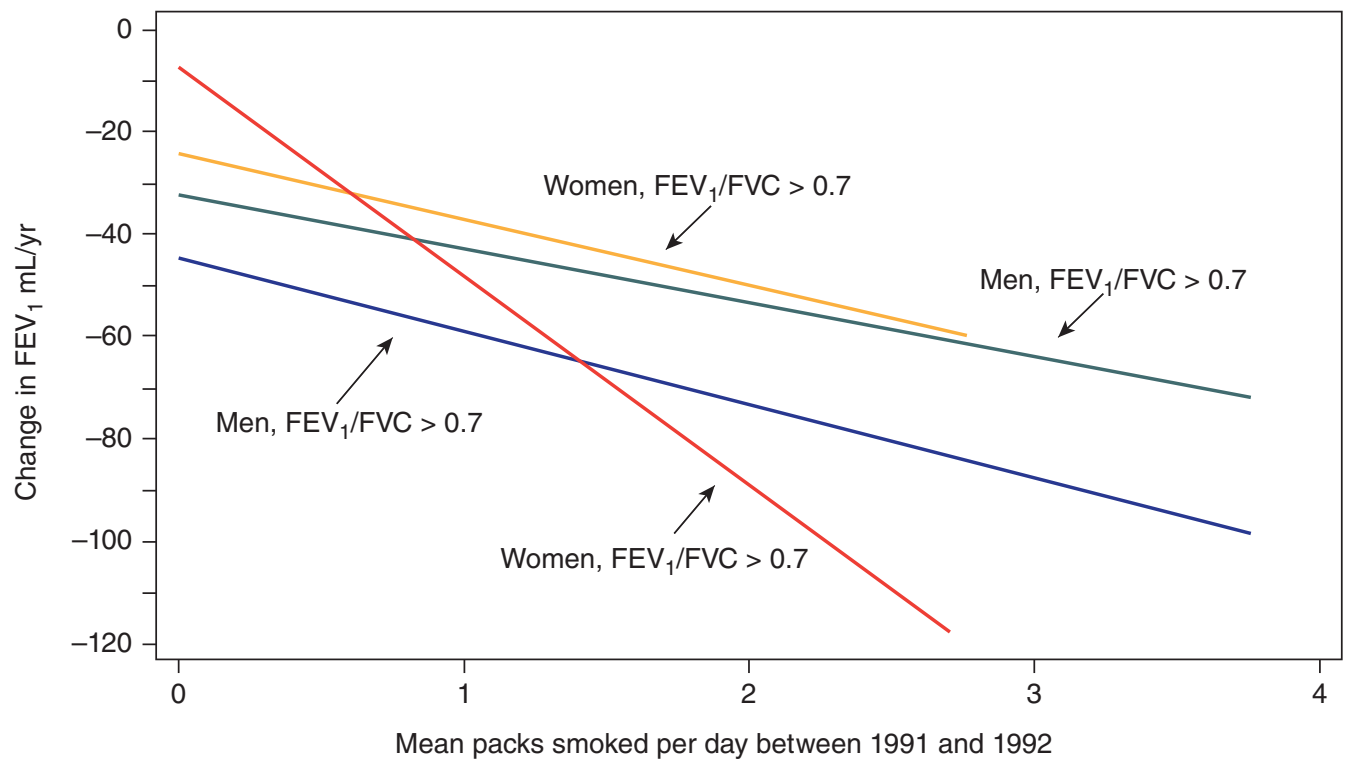

FigURE 1. Relation between mean packs per day and annual change in FEV F $_{1}$ in men and women between 1991 and 1992 taken from regression models developed from the Swiss cohort Study on Air Pollution and Lung and Heart Diseases in Adults (SALPADIA) (reproduced with permission from Downs SH et al. ${ }^{13}$ ).

$\mathrm{FEV}_{1}$ : forced expiratory volume in 1 second forced; FVC: forced vital capacity.

greater probability of having airway obstruction with a lower self-reported cigarette smoke exposure among women, and women were at increased risk of airflow obstruction after only 15 years of smoking and five cigarettes per day.

Global smoking patterns are changing and it is estimated that the proportion of women who smoke will rise from approximately $12 \%$ in the first decade of this century to $20 \%$ by $2025^{21}$. This will be especially prominent in low- and middle-income regions, while the proportion of women who smoke in high-income regions are expected to progressively fall over the same period. Despite being signatories to the World Health Organization (WHO) Convention on Tobacco Control, many low-middle income countries do not enforce the regulation of tobacco and promotion of tobacco products.
The effects of air pollution consequent on urbanisation and rapid development of many previously predominantly rural countries in Asia, are also likely to have profound impacts on women, both as a synergistic effect with tobacco smoke exposure, and as a direct consequence of airway inflammation secondary to high levels of pollution, although it is not known whether women are more susceptible to atmospheric pollutants from car and diesel emissions ${ }^{12}$. Nor has it been proven that outdoor air pollution alone causes obstructive airways disease, although evidence from a number of sources suggest this is likely ${ }^{22-25}$. Between 2010 and 2025, in the urban population of China alone, prevalent cases of COPD will grow from about 18.5 million to approximately 30 million $^{26-28}$. Around the world, longevity and urbanisation are likely to contribute to an increasing burden of COPD and 
costs attributable to work time lost, productivity loss, disability and premature death $22,23,29-31$.

In low-tomiddle income countries, the rise in smoking prevalence in women has been less marked than in high-income countries, however this is changing as young women move to cities, and are exposed to advertising and relatively cheap tobacco. COPD rates in women who are lifelong nonsmokers, are relatively high ${ }^{28-31}$. This is a result of multiple different risk factors experienced by women in these countries, including smoke exposure from cooking and heating using biomass fuels, occupational exposures in cottage industries in poorly ventilated workplaces and no protective clothing, and additional, poorly documented exposures such as from wildfires and forest burning 32,33 . The use of biomass fuel for cooking and smoking is relatively high in many parts of the world ${ }^{34-37}$, and is likely to particularly affect women and children for decades to come, despite vigorous efforts to introduce clean cookstoves and to improve external venting of woodstove smoke using simple flues ${ }^{38-40}$. Additionally, it is now understood that there are different trajectories to the development of $\mathrm{COPD}^{41}$, and early life factors such as premature birth, poor nutrition, smoke and fume exposure and recurrent respiratory infections are risk factors for not achieving predicted normal values for airway function by early adult life $28.37,42-44$. The sex-related aspects of these have not yet been explored.

\section{Potential explanations for the increased susceptibility of women to smoke exposure}

There are many possible contributors to the increased propensity of women to develop COPD in response to similar or lower exposures than men. The reduced surface area of women's bronchial mucosa, combined with their smaller airways means there is a potentially greater exposure to toxic inhalations and particulates when considered as dose $/ \mathrm{mm}^{345}$. There are also important differences between men and women in inhalation pattern, depth, frequency, exhalation and breath hold. Varying sensitivity during different stages of life $^{46}$, or the menstrual cycle may play a role, in addition to important genetic determinants of susceptibility that are only now being identified ${ }^{17,18,47}$. In the Lung Health Study, female smokers had greater levels of airway hyperresponsiveness and this was higher in continuing smokers than quitters, predisposing women to the increased risk of developing airflow limitation consequent on a combination of airway hyperresponsiveness (AHR) and smoking ${ }^{48}$. However, a great deal more research is needed to understand how sex influences the effects of smoking on airway molecular structures, epithelial inflammation, lung function, severity of emphysema, progression of COPD and the downstream high prevalence of symptoms and risk of exacerbations ${ }^{49}$. Our lack of knowledge in this area will almost certainly have an influence on finding solutions to limit the damage of smoking in women.

\section{The natural history of COPD in women}

Women may also experience different trajectories of COPD, especially after ceasing smoking. During three years of the European Respiratory Society's study on chronic obstructive pulmonary disease (EUROSCOP) ${ }^{50}$, in a relatively milder population, there were cross-sectional and longitudinal differences between men and women in symptom prevalence, response to 
smoking and treatment. Similar proportions of men and women reported symptoms, although in men better lung function was associated with improvement in wheeze and dyspnoea, and symptom prevalence reduced with annual $\mathrm{FEV}_{1}$ improvement. The prevalence of phlegm also reduced with budesonide treatment, and was limited to men. Men were also more likely to record an increase in phlegm and wheeze when the number of cigarettes smoked between visits increased. Symptom reporting by men in general appeared to reflect disease activity - either improvement or decline as measured by $\mathrm{FEV}_{1} \%$ predicted. Longitudinally it appeared also that in men particularly, symptoms are a good predictor of disease status, but this was not so evident in women.

In the Lung Health Study, women had more AHR and $\mathrm{FEV}_{1}$ declined at a similar rate if they continued to smoke, but had a greater improvement in their $\mathrm{FEV}_{1}$ after smoking cessation and a significantly lower rate of $\mathrm{FEV}_{1}$ decline than men ${ }^{48,51,52}$.

\section{SYMPTOM PRESENTATION IN WOMEN}

It is now well accepted that men and women respond differently to the presence of symptoms, recommendations for treatment, both prior to diagnosis and when a diagnosis is established ${ }^{53,54}$. Additionally, there are differences in the frequency of particular COPD phenotypes affecting men and women. Women appear more likely to exhibit small airway disease (bronchiolitis), whereas men are more prone to develop an emphysematous phenotype ${ }^{55-58}$. It is well recognized that women who develop COPD from biomass exposure are more likely to develop a chronic bronchitic, mucus hypersecretion phenotype, but in relation to tobacco smoking also, women are more likely to present with airway predominant features ${ }^{34,59}$, especially chronic bronchitis and wheeze ${ }^{60}$. Women have more severe symptoms when they do have an emphysema phenotype ${ }^{49}$ but in most studies still have a better life expectancy ${ }^{61}$.

\section{Missed and mis-diagnosis}

Several studies have shown that women are also more likely to be given an asthma diagnosis, even when they have a significant smoking history. This is especially the case in countries where smoking prevalence is traditionally much higher in men, resulting in a higher rate of misdiagnosis in women with COPD compared with men, potentially leading to suboptimal treatment ${ }^{62-65}$. In one Canadian study, when spirometry was added, a COPD diagnosis became more probable ${ }^{66}$. Although the gender bias in diagnosis is reduced by the use of spirometry, spirometry in general remains underused, particularly in women ${ }^{63}$. This is especially so in primary care where most patients receive their initial diagnosis of $\mathrm{COPD}^{67-69}$, giving a higher probability that women will not receive a COPD diagnosis when that is the true nature of their disease.

Prominent airway symptoms, along with a higher prevalence of AHR in women may partly account for this tendency to more readily diagnose asthma than COPD in women ${ }^{51}$. A number of investigators have shown that women are more likely to experience delay in the diagnosis of COPD even though they may present earlier ${ }^{65}$. In part, this appears to be a consequence of being more likely to receive an asthma diagnosis than men, even with a similar 


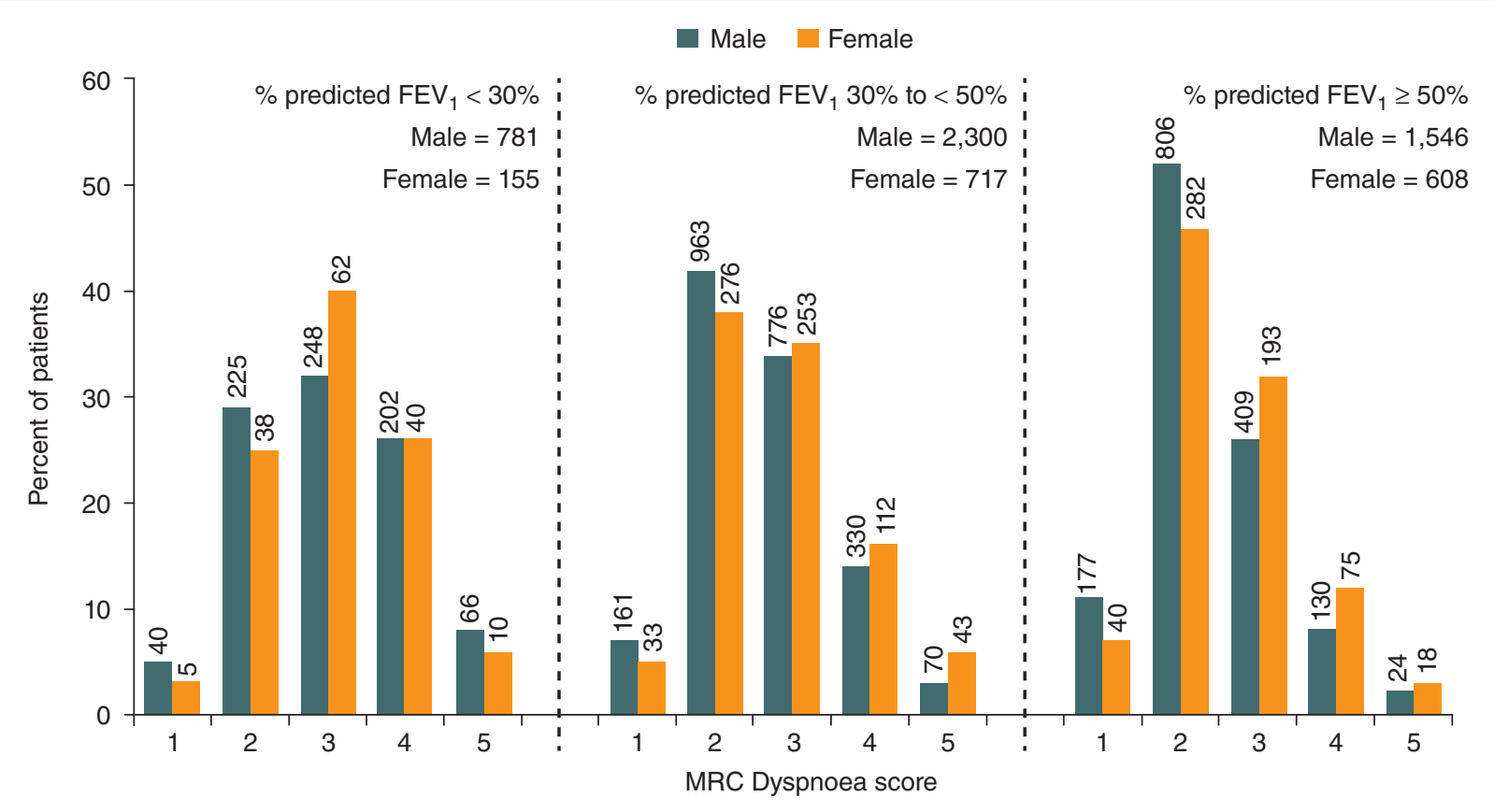

FIGURE 2. Medical Research Council (MRC) Dyspnoea ${ }^{0}$ scores by sex. In each stage females had worse scores than males $(p<0.0001)$ (reproduced with permission from Celli $B$ et al. .85 ).

$\mathrm{FEV}_{1}$ : forced expiratory volume in 1 second forced.

smoking history, when COPD is present. As different treatment strategies are applied to asthma and COPD, and inhaled corticosteroid ICS)-long-acting $\beta 2$-agonist (LABA) is not necessarily the correct treatment for both, it is important that where possible the two diseases are correctly identified and managed.

Women appear to experience different spectrum and severity of symptoms for a given severity of spirometric abnormality. In a Spanish study ${ }^{70}$, women were younger, smoked less, had better $\mathrm{PaO}_{2}$ and lower $\mathrm{PaCO}_{2}$, but more exacerbations in the last year and fewer comorbidities however they performed poorer in walking distance, had worse St George's Respiratory Questionnaire (SGRQ) total, symptoms and activity scores, and had a higher degree of dyspnaea. Comorbidities have been shown to be different in a range of studies, with a greater predominance of anxiety, depression, osteoporosis and sleep disturbance but a lower prevalence of cardiovascular diagnoses ${ }^{54,65,71}$.

Several studies show that for a similar degree of airway obstruction, women have worse scores on health status questionnaires than men, including for SGRQ domains ${ }^{72}$, and worse dyspnoea scores such as on Medical Research Council (MRC) (Fig. 2). Women may also experience greater psychosocial impairment related to COPD than men ${ }^{73}$ and have greater levels of anxiety and depression ${ }^{74-78}$. This aligns with studies demonstrating lower scores in the mental component of the short form (SF)-12 health status questionnaire compared with men ${ }^{71}$. 
Though women may more frequently report some symptoms such as dyspnoea and wheeze, this is not the case for all symptoms and they may not be as sensitive to change as in men. Women have been noted to be less likely to report phlegm but for a given level of airflow obstruction, experience a greater impact on exercise capacity, breathlessness and quality of life. In a Spanish study ${ }^{70}$, in men and women matched for severity of airflow limitation, women tended to be younger, to have smoked less in total pack years, and have better oxygenation. Despite this they performed less well in walking distance and had worse quality of life scores and a higher degree of dyspnoea at iso-exercise.

In a primary care setting in Canada, the clinical presentation and historical features in ever smokers was assessed by symptom questionnaires and spirometry ${ }^{79}$. Men smoked significantly more than women and were more likely to have an abnormal $\mathrm{FEV}_{1}$ /vital capacity (VC) ratio but more women than men reported breathlessness, a previous diagnosis compatible with airway obstruction and were taking respiratory medications.

\section{Acute exacerbations of COPD}

Several studies report a higher rate of exacerbations in women versus men with $\mathrm{COPD}^{60}$, although generally women have better short- and long-term survival after severe exacerbations requiring hospitalization ${ }^{4,61}$. This is despite the fact that mortality rates in many high- income countries are increasing for women and declining for men ${ }^{80,81}$, and in some, women's COPD-mortality rates are now higher overall ${ }^{82}$. Exacerbation rates and symptom burden have been higher in women recruited into several large COPD clinical trials as well as in large population cohorts ${ }^{60}$. In the Evaluation of COPD Longitudinally to Identify Predictive Surrogate End-points (ECLIPSE) cohort, the rate of exacerbations was significantly higher in women than men at each GOLD stage ${ }^{83}$. In a post-hoc analysis of the Prevention of Exacerbations with Tiotropium in Chronic Obstructive Pulmonary Disease (POET-COPD) trial, the risk of first exacerbation was higher for women compared with men (hazard ratio [HR] 1.31; 95\% CI: 1.19-1.43) ${ }^{84}$. In the TOwards a Revolution in COPDHealth (TORCH) study, the time to first exacerbation was shorter and the rate of exacerbations was $25 \%$ higher in women than in men ( $<<0.001 ; 95 \%$ CI: 16-34), (Fig. 3), although the number of hospital admissions caused by exacerbations was simi$\operatorname{lar}^{85}$. Although several studies show that women are more likely to be admitted to hospital for an exacerbation ${ }^{86}$ (Fig. 4), they appear less likely to die in hospital ${ }^{87}$. In a population of $>$ 40,000 participants in the Quebec Insurance databases, males had a significantly increased risk of death (adjusted HR 1.45; 95\% CI: 1.42-1.49) and re-hospitalisation for COPD (adjusted HR 1.12; 95\% CI: 1.09- 1.15) 88 .

\section{Response to treatment}

Smoking cessation is the most important initial step in COPD management. The Lung Health Study suggests that women may benefit more from smoking cessation than men, even though other studies suggest they may have more difficulty giving up ${ }^{89,90}$. There are no studies designed to examine sex-related differences in the effects of nicotine replacement therapy and smoking cessation medications (such as bupropion and varenicline) appear to be equally effective in men and women ${ }^{64,91-93}$. As women 


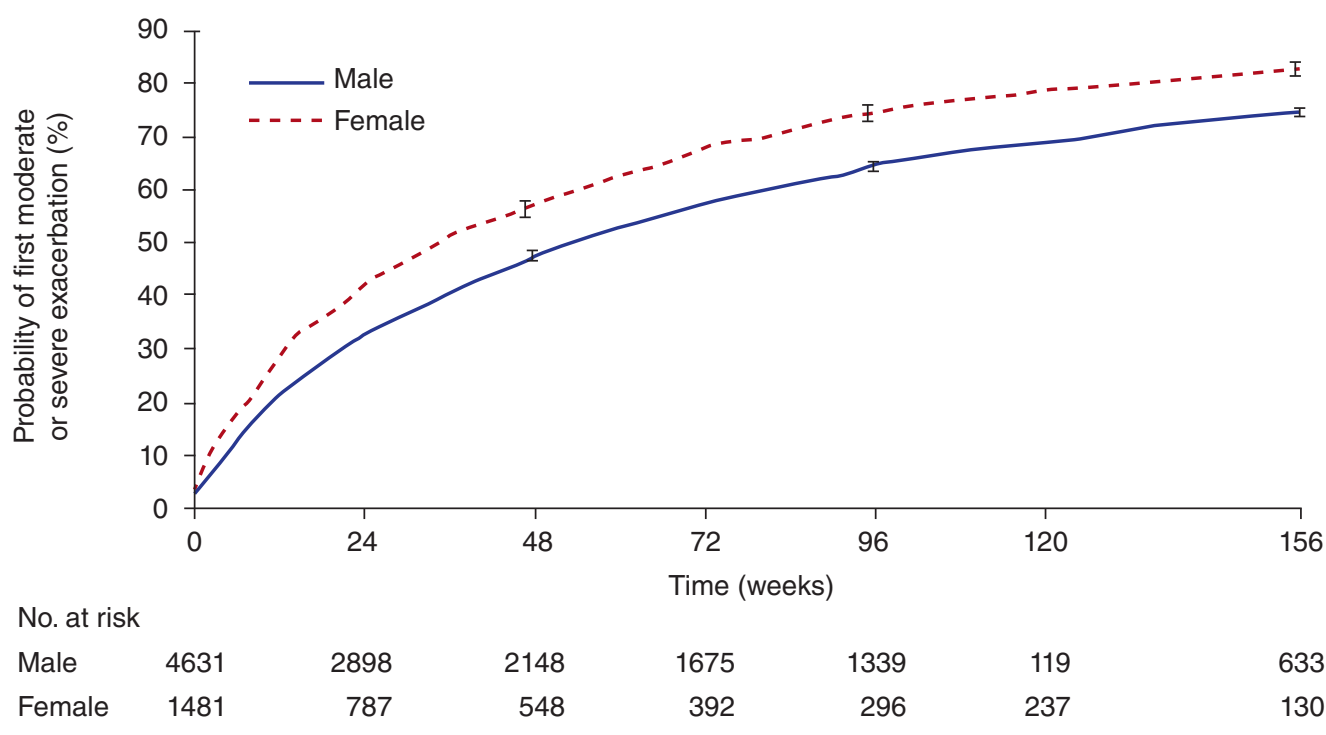

Figure 3. Kaplan-Meier graph of time to first moderate to severe exacerbation. Bars are standard errors (reproduced with permission from Celli $B$ et al. ${ }^{85}$.

may have greater levels of anxiety and greater smoking dependence than men, they may benefit also from a tailored behavioural approach ${ }^{93}$. Pulmonary rehabilitation is also a key non-pharmacologic intervention for patients with COPD, but very few studies report any differences between men and women and most enrol more males than females.

In pharmacologic trials, very rarely are gendered analyses undertaken, studies are underpowered for analyses based on sex, particularly when women are underrepresented. In the EUROSCOP study ${ }^{50}$, as already mentioned, the improvement in phlegm on budesonide was limited to men. Longitudinally, men showed a greater response based on their symptom reporting to cigarette exposure (worsening) and treatment (improvement). Women initially reported greater remission of symptoms in the

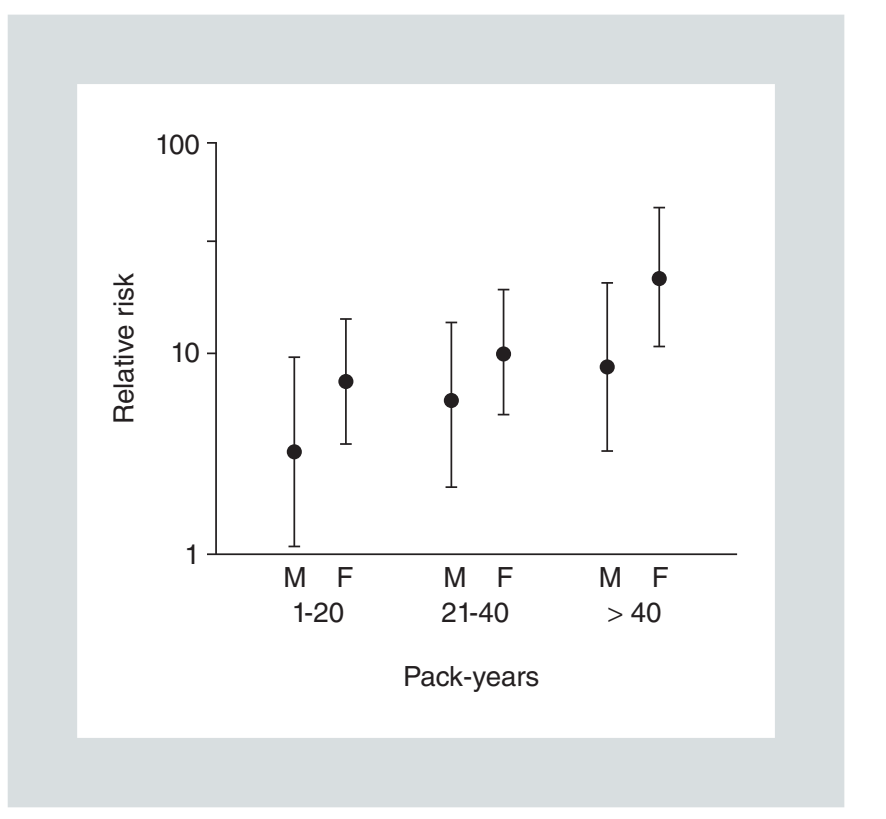

Figure 4. Age-adjusted relative risk of hospitalization for chronic obstructive pulmonary disease (COPD) by pack years among smokers who inhaled, in the Copenhagen City Heart Study (CCHS). Lifelong nonsmokers and smokers who did not inhale were used as reference. Note the logarithmic scale (reproduced with permission from Prescott $E$ et al. $\left.{ }^{86}\right)$.

F: female; M: male. 
first year of follow-up but over the three-year period the symptom prevalence differences between men and women disappeared.

Considering the increasing and expansive literature on COPD management, it is lamentable that there are so few studies or analyses of clinical trials to support physicians with gender-focused pharmacological treatment of $\mathrm{COPD}^{94}$. Current guidelines are largely based on clinical trials that have recruited many more men than women ${ }^{95-97}$. The lack of gender-specific recommendations could be because there is no difference in the effectiveness or efficacy of treatments, however, this is not known. Analyses suggest that clinical trials populations differ from real-world patients particularly in gender distribution. As the rate of smoking in women has increased and will inevitably be reflected in increased COPD morbidity and mortality in future decades, there is an urgent need for future trials to redress this imbalance. Further, as many women and children in low-income countries will be exposed to biomass fuels for heating and cooking for decades to come, specific studies examining the effects of treatment in these women with a biomass-chronic bronchitis phenotype of COPD are urgently needed. Randomised controlled trials should adopt strategies to recruit and retain women, and to pre-specify sub-analyses based on gender in order to assess responses to treatment and their determinants. Systematic reviews and meta-analyses, as well as less robust but potentially informative post-hoc analyses should be undertaken to explore gender related treatment effects and to plan future studies. These analyses would be hypothesis generating and would help identify differential effects of treatment and target therapy to reduce the impact of COPD in both men and women.

\section{SUMMARY}

There are many differences between men and women in risk factor impact, symptom development, presentation, clinical manifestations and outcomes of COPD. Women's greater risk of developing COPD at lower doses of tobacco, and the continuing exposure of women to biomass cooking and heating fuels in many parts of the world make it probable that globally, women will ultimately have a higher prevalence of COPD than men. In relation to treatment, the differences between men and women's responses have been very inadequately explored, which is of particular concern in view of the increasing prevalence and high symptom burden of disease in women. Research addressing sex-related aspects of COPD is urgently needed. The time is well overdue for a gendered approach to study design and treatment assessment, which would enable us to take a step closer to tailored management of COPD in women.

\section{CONFLICT OF INTEREST}

Dr. Christine Jenkins receives honoraria and travel payment to participate on advisory boards and steering committees and to present at educational symposia for several Pharmaceutical companies including AstraZeneca, Boehringer Ingelheim, GlaxoSmithKline, MedImmune and Novartis. Her institution receives funding from several companies to undertake clinical research and support fellowships.

\section{REFERENCES}

1. Gershon AS, Warner L, Cascagnette P, Victor JC, To T. Lifetime risk of developing chronic obstructive pulmonary disease: a longitudinal population study. Lancet. 2011;378:991-6.

2. Burney PG, Patel J, Newson R, Minelli C, Naghavi M. Global and regional trends in COPD mortality, 1990-2010. Eur Respir J. 2015;45:1239-47. 
3. Adeloye D, Chua S, Lee C et al. Global and regional estimates of COPD prevalence: Systematic review and meta-analysis. J Glob Health. 2015;5:020415.

4. Doucet M, Rochette L, Hamel D. Incidence, Prevalence, and Mortality Trends in Chronic Obstructive Pulmonary Disease over 2001 to 2011: A Public Health Point of View of the Burden. Can Respir J. 2016;2016:7518287.

5. Soriano J, Maier W, Egger P et al. Recent trends in physician diagnosed COPD in women and men in the UK. Thorax. 2000;55:789-94.

6. Prescott E, Bjerg AM, Andersen PK, Lange P, Vestbo J. Gender difference in smoking effects on lung function and risk of hospitalization for COPD: results from a Danish longitudinal population study. Eur Respir J. 1997;10(4):822-7.

7. Ulrick CS. Smoking and mortality in women: "smoke like a man, die (at least) like a man". Eur Resp Monograph. 2003;25:103-17.

8. Buist As, McBurnie MA, Vollmer WM et al. International variation in the prevalence of COPD (The BOLD Study): a population-based prevalence study. Lancet 2007;370:741.

9. Sørheim I-C, Johannessen A, Gulsvik A, Bakke PS, Silverman EK, DeMeo DL. Gender differences in COPD: are women more susceptible to smoking effects than men? Thorax. 2010;65:480-5.

10. Amaral AFS, Strachan DP, Burney PGJ, Jarvis DL. Female Smokers Are at Greater Risk of Airflow Obstruction Than Male Smokers. UK Biobank. Am J Respir Crit Care Med. 2017;195:1226-35.

11. Sansores RH, Ramirez-Venegas A. COPD in women: susceptibility or vulnerability? Eur Respir J. 2016;47:19-22.

12. Wang B, Xiao D, Wang C. Smoking and chronic obstructive pulmonary disease in Chinese population: a meta-analysis. Clin Respir J. 2015;9:165-75.

13. Downs SH, Brandli O, Zellweger JP et al. Accelerated decline in lung function in smoking women with airway obstruction: SAPALDIA 2 cohort study. Respir Res. 2005;6:45.

14. Ben-Zaken Cohen S, Pare PD, Man SF, Sin DD. The growing burden of chronic obstructive pulmonary disease and lung cancer in women: examining sex differences in cigarette smoke metabolism. Am J Respir Crit Care Med. 2007;176:113-20.

15. Becklake M, Kauffmann F. Gender Differences in airway behaviour over the human lifespan. Thorax. 1999;54:1119-38.

16. Barnes P. Sex Differences in Chronic Obstructive Pulmonary Disease Mechanisms. Am J Resp Crit Care Med. 2016;193:813-4.

17. Tam A, Churg A, Wright JL et al. Sex Differences in Airway Remodeling in a Mouse Model of Chronic Obstructive Pulmonary Disease. Am J Respir Crit Care Med. 2016;193:825-34.

18. Hardin M, Cho MH, Sharma S et al. Sex-Based Genetic Association Study Identifies CELSR1 as a Possible Chronic Obstructive Pulmonary Disease Risk Locus among Women. Am J Respir Cell Mol Biol. 2017;56:332-41.

19. Xu F, Yin X, Zhang M, Shen H, Lu L. Prevalence of Physician-Diagnosed COPD and Its Association With Smoking Among Urban and Rural Residents in Regional Mainland China. Chest. 2005;128:2813-23.

20. Laitinen T HU, Kupiainen H, Tammilehto L et al. Real-World Clinical Data Identifies Gender-related Profiles in Chronic Obstructive Pulmonary Disease. COPD. 2009;6:256-62.

21. World Health Organization (WHO). Empower women - combating tobacco industry marketing in the WHO European region. 2010. Last accessed 15 December 20152010. Available from: http://www.euro.who.int/_data/ assets/pdf_file/0014/128120/e93852.pdf.

22. Maji KJ, Dikshit AK, Deshpande A. Disability-adjusted life years and economic cost assessment of the health effects related to $\mathrm{PM}_{2.5}$ and $\mathrm{PM}_{10}$ pollution in Mumbai and Delhi, in India from 1991 to 2015. Environ Sci Pollut Res Int. 2017;24:4709-30.

23. Liu S, Zhou Y, Liu S et al. Association between exposure to ambient particulate matter and chronic obstructive pulmonary disease: results from a cross-sectional study in China. Thorax. 2017;72:788-95.

24. Ko FWS, Hui DSC. Air pollution and chronic obstructive pulmonary disease. Respirology. 2012;17:395-401.

25. Guan WJ, Zheng XY, Chung KF, Zhong NS. Impact of air pollution on the burden of chronic respiratory diseases in China: time for urgent action. Lancet. 2016;388:1939-51.
26. Kelly FJ, Fussell JC. Air pollution and airway disease. Clin Exp Allergy. 2011;41:1059-71.

27. Lindgren A, Stroh E, Montnemery P, Nihlen U, Jakobsson K, Axmon A. Traffic-related air pollution associated with prevalence of asthma and COPD/chronic bronchitis. A cross-sectional study in Southern Sweden. Int J Health Geogr. 2009;8:2.

28. Smith M, Li L, Augustyn M et al. Prevalence and correlates of airflow obstruction in 317,000 never-smokers in China. Eur Respir J. 2014;44:66-77.

29. Sadhra S, Kurmi OP, Sadhra SS, Lam KB, Ayres JG. Occupational COPD and job exposure matrices: a systematic review and meta-analysis. Int J Chron Obstr Pulmon Dis. 2017;12:725-34.

30. McLean S, Barbour V, Wild S, Simpson C, Sheikh A. Models for estimating projections for disease prevalence and burden: a systematic review focusing on chronic obstructive pulmonary disease. J Health Serv Res Policy. 2015;20: 246-53.

31. Fragoso CA. Epidemiology of Chronic Obstructive Pulmonary Disease (COPD) in Aging Populations. COPD. 2016;13:125-9.

32. Golpe R, Mengual-Macenlle N, Sanjuan-Lopez P, Cano-Jimenez E, Castro-Anon O, Perez-de-Llano LA. Prognostic Indices and Mortality Prediction in COPD Caused by Biomass Smoke Exposure. Lung. 2015;193:497-503.

33. Kurmi OP, Semple S, Simkhada P, Smith WC, Ayres JG. COPD and chronic bronchitis risk of indoor air pollution from solid fuel: a systematic review and meta-analysis. Thorax. 2010;65:221-8.

34. Regalado J, Perez-Padilla R, Sansores R et al. The effect of biomass burning on respiratory symptoms and lung function in rural Mexican women. Am J Respir Crit Care Med. 2006;174:901-5.

35. Torres-Duque C, Maldonado D, Perez-Padilla R, Ezzati M, Viegi G, Forum of International Respiratory Studies Task Force on Health Effects of Biomass E. Biomass fuels and respiratory diseases: a review of the evidence. Proc Am Thorac Soc. 2008;5:577-90.

36. Johnson P, Balakrishnan K, Ramaswamy P et al. Prevalence of chronic obstructive pulmonary disease in rural women of Tamilnadu: implications for refining disease burden assessments attributable to household biomass combustion. Global health action. 2011;4:7226.

37. Piddock KC, Gordon SB, Ngwira A et al. A cross-sectional study of household biomass fuel use among a periurban population in Malawi. Ann Am Thor Soc. 2014;11:915-24.

38. Barnes PJ. Is Exposure to Biomass Smoke the Biggest Risk Factor for COPD Globally? CHEST Journal. 2010;138:5:3-6.

39. D P, Bruce N, Dherani M, Jagoe K, E. R. Real-life effectiveness of 'improved' stoves and clean fuels in reducing PM2.5 and CO: Systematic review and meta-analysis. Environment International 2017;101.

40. Mortimer K. Chimney stove intervention--ready for scale up? CON. Thorax. 2016;71:391-2.

41. Lange P, Celli B, Agusti A et al. Lung-Function Trajectories Leading to Chronic Obstructive Pulmonary Disease. N Engl J Med. 2015;373:111-22.

42. Berry CE, Billheimer D, Jenkins IC et al. A Distinct Low Lung Function Trajectory from Childhood to the Fourth Decade of Life. Am J Respir Crit Care Med. 2016;194:607-12.

43. Barone-Adesi F, Dent JE, Dajnak D et al. Long-Term Exposure to Primary Traffic Pollutants and Lung Function in Children: Cross-Sectional Study and Meta-Analysis. PLoS ONE. 2015;10:e0142565.

44. Schultz ES, Hallberg J, Bellander T et al. Early-Life Exposure to Traffic-related Air Pollution and Lung Function in Adolescence. Am J Respir Crit Care Med. 2016;193:171-7.

45. Sorheim IC, Johannessen A, Gulsvik A, Bakke PS, Silverman EK, DeMeo DL. Gender differences in COPD: are women more susceptible to smoking effects than men? Thorax. 2010;65:480-5.

46. Gan WQ, Man SF, Postma DS, Camp P, Sin DD. Female smokers beyond the perimenopausal period are at increased risk of chronic obstructive pulmonary disease: a systematic review and meta-analysis. Respir Res. 2006;7:52.

47. Carlson CL, Cushman M, Enright PL, Cauley JA, Newman AB. Hormone replacement therapy is associated with higher FEV1 in elderly women. Am J Respir Crit Care Med. 2001;163:423-8.

48. Connett JE, Murray RP, Buist AS et al. Changes in smoking status affect women more than men: results of the Lung Health Study. Am J Epidemiol. 2003;157:973-9. 
49. Martinez FJ, Curtis JL, Sciurba F et al. Sex differences in severe pulmonary emphysema. Am J Respir Crit Care Med. 2007;176:243-52.

50. Watson L, Schouten JP, Lofdahl CG et al. Predictors of COPD symptoms: does the sex of the patient matter? Eur Respir J. 2006;28:311-8.

51. Anthonisen NR. Lessons from the Lung Health Study. Proc Am Thorac Soc. 2004;1:143-5.

52. Anthonisen NR. Smoking and Lung Function of Lung Health Study Participants after 11 Years. Am J Respir Crit Care Med. 2002;166:675-9.

53. Barsky AJ PH, Borus JF. Somatic Symptom Reporting in Women and Men. J Gen Intern Med. 2001;16:266-75.

54. Watson L, Vestbo J, Postma DS et al. Gender differences in the management and experience of Chronic Obstructive Pulmonary Disease. Respir Med. 2004;98:1207-13.

55. Hardin M, Foreman M, Dransfield MT et al. Sex-specific features of emphysema among current and former smokers with COPD. Eur Respir J. 2016;47:104-12.

56. Camp PG, Coxson HO, Levy RD et al. Sex differences in emphysema and airway disease in smokers. Chest. 2009;136:1480-8.

57. Han MK, Kazerooni EA, Lynch DA et al. Chronic obstructive pulmonary disease exacerbations in the COPDGene study: associated radiologic phenotypes. Radiology. 2011;261:274-82.

58. Martinez FJ, Curtis JL, Sciurba F et al. Sex differences in severe pulmonary emphysema. Am J Respir Crit Care Med. 2007;176:243-52.

59. Po JY, FitzGerald JM, Carlsten C. Respiratory disease associated with solid biomass fuel exposure in rural women and children: systematic review and meta-analysis. Thorax. 2011;66:232-9.

60. Sundh J, Johansson G, Larsson K et al. The phenotype of concurrent chronic bronchitis and frequent exacerbations in patients with severe COPD attending Swedish secondary care units. Int J Chron Obstruct Pulmon Dis. 2015;10:2327-34.

61. de Torres JP, Cote CG, Lopez MV et al. Sex differences in mortality in patients with COPD. Eur Respir J. 2009;33:528-35.

62. Ancochea J, Miravitlles M, García-Río F et al. Underdiagnosis of chronic obstructive pulmonary disease in women: quantification of the problem, determinants and proposed actions. Arch Bronconeumol. 2013;49:223-9.

63. Chapman KR, Tashkin DP, Pye DJ. Gender bias in the diagnosis of COPD. Chest. 2001;119:1691-5.

64. Han MK, Postma D, Mannino DM et al. Gender and chronic obstructive pulmonary disease: why it matters. Am J Respir Crit Care Med. 2007;176:1179-84.

65. Martinez CH, Raparla S, Plauschinat CA et al. Gender differences in symptoms and care delivery for chronic obstructive pulmonary disease. J Womens Health (Larchmt). 2012;21:1267-74

67. Miravitlles M, Andreu I, Romero Y, Sitjar S, Altes A, Anton E. Difficulties in differential diagnosis of COPD and asthma in primary care. Br J Gen Pract. 2012;62:e68-75.

68. Llordes M, Jaen A, Almagro P et al. Prevalence, Risk Factors and Diagnostic Accuracy of COPD Among Smokers in Primary Care. COPD. 2015;12: 404-12.

69. Barrecheguren M, Monteagudo M, Ferrer J et al. Treatment patterns in COPD patients newly diagnosed in primary care. A population-based study. Respir Med. 2016;111:47-53.

70. de Torres J, Casanova C, Hernández C, Abreu J, Aguirre-Jaime A, Celli BR. Gender and COPD in Patients Attending a Pulmonary Clinic. Chest. 2005; 128:2012-6

71. Carrasco-Garrido P, de Miguel-Diez J, Rejas-Gutierrez J et al. Characteristics of chronic obstructive pulmonary disease in Spain from a gender perspective. BMC Pulm Med. 2009;9:2.

72. Ferrari R, Tanni SE, Lucheta PA, Faganello MM, do Amaral RA, Godoy I. Gender differences in predictors of health status in patients with COPD. J Bras Pneumol. 2010;36:37-43.

73. Low G, Gutman G. Examining the role of gender in health-related quality of life: Perceptions of older adults with chronic obstructive pulmonary disease. Journal of gerontological nursing. 2006;32:42-9.

74. Naberan K, Azpeitia A, Cantoni J, Miravitlles M. Impairment of quality of life in women with chronic obstructive pulmonary disease. Respir Med. 2012; 106:367-73.
76. Dowson C, Laing R, Barraclough R et al. The use of the Hospital Anxiety and Depression Scale (HADS) in patients with chronic obstructive pulmonary disease: a pilot study. N Z Med J. 2001;114:447-9.

77. Gudmundsson G, Gislason T, Janson C et al. Depression, anxiety and health status after hospitalisation for COPD: a multicentre study in the Nordic countries. Respir Med. 2006;100:87-93.

78. Raherison C, Tillie-Leblond I, Prudhomme A et al. Clinical characteristics and quality of life in women with COPD: an observational study. BMC women's health. 2014;14:31.

79. Dales RE, Mehdizadeh A, Aaron SD, Vandemheen KL, Clinch J. Sex differences in the clinical presentation and management of airflow obstruction. Eur Respir J. 2006;28:319-22.

80. Mannino D, Brown C, Giovino G. Obstructive Lung Disease Deaths in the United States from 1979 through 1993 An Analysis Using Multiple-Cause Mortality Data. Am J Respir Crit Care Med. 1997;156:814-8.

81. Gershon A, Hwee J, Victor JC et al. Mortality trends in women and men with COPD in Ontario, Canada, 1996-2012. Thorax. 2015;70:121-6.

82. Ringbaek T, Seersholm N, Viskum K. Standardised mortality rates in females and males with COPD and asthma. Eur Respir J. 2005;25:891-5.

83. Agusti A, Calverley PM, Celli B et al. Characterisation of COPD heterogeneity in the ECLIPSE cohort. Respir Res. 2010;11:122.

84. Beeh KM, Glaab T, Stowasser S et al. Characterisation of exacerbation risk and exacerbator phenotypes in the POET-COPD trial. Respir Res. 2013;14:116.

85. Celli B, Vestbo J, Jenkins CR et al. Sex differences in mortality and clinica expressions of patients with chronic obstructive pulmonary disease. The TORCH experience. Am J Respir Crit Care Med. 2011;183:317-22.

86. Prescott E, AM B, Andersen PK, Lange P, Vestbo J. Gender difference in smoking effects on lung function and risk of hospitalization for COPD: results from a Danish longitudinal population study. Eur Respir J. 1997;10:822-7.

87. Ekstrom MP, Jogreus C, Strom KE. Comorbidity and sex-related differences in mortality in oxygen-dependent chronic obstructive pulmonary disease. PLoS ONE. 2012;7:e35806.

88. Gonzalez AV, Suissa S, Ernst P. Gender differences in survival following hospitalisation for COPD. Thorax. 2011;66:38-42.

89. Connett JE, Murray RP, Buist AS et al. Changes in smoking status affect women more than men: results of the Lung Health Study. Am J Epidemiol. 2003;157:973-9

90. Vozoris NT, Stanbrook MB. Smoking prevalence, behaviours, and cessation among individuals with COPD or asthma. Respir Med. 2011;105:477-84.

91. Aryal S, Diaz-Guzman E, Mannino DM. Influence of sex on chronic obstructive pulmonary disease risk and treatment outcomes. Int J Chron Obstruc Pulmon Dis. 2014;9:1145-54.

92. Gonzales D, Rennard SI, Nides M et al. Varenicline, an alpha4beta2 nicotini acetylcholine receptor partial agonist, vs sustained-release bupropion and placebo for smoking cessation: a randomized controlled trial. JAMA. 2006;296:47-55.

93. Rahmanian SD, Diaz PT, Wewers ME. Tobacco use and cessation among women: research and treatment-related issues. J Womens Health (Larchmt). 2011;20:349-57

94. Becklake MR, Kauffmann F. Gender differences in airway behaviour over the human life span. Thorax. 1999;54:1119-38.

95. Bateman ED, Ferguson GT, Barnes N et al. Dual bronchodilation with QVA149 versus single bronchodilator therapy: the SHINE study. Eur Respir J. 2013;42:1484-94.

96. Decramer M, Anzueto A, Kerwin E et al. Efficacy and safety of umeclidinium plus vilanterol versus tiotropium, vilanterol, or umeclidinium monotherapies over 24 weeks in patients with chronic obstructive pulmonary disease: result from two multicentre, blinded, randomised controlled trials. Lancet Respi Med. 2014;2:472-86.

97. Global initiative for chronic Obstructive Lung Disease (GOLD). Global strategy for the diagnosis, management, and prevention of chronic obstructive pulmonary disease. Updated 2015. Last accessed 17 November 2015 wwwgoldcopdorg/uploads/users/files/GOLD_Report_2015pdf [Internet] 2015. Available from: http://www.goldcopd.org/uploads/users/files/GOLD_ Report_2015.pdf. 